\title{
Gonadotrophin in the term placenta of the dolphin (Tursiops truncatus), the Californian sea lion (Zalophus californianus), the grey seal (Halichoerus grypus) and man
}

\author{
B. M. Hobson and L. Wide* \\ Department of Obstetrics \& Gynaecology, University of Edinburgh, Edinburgh EH8 9AG, U.K. and \\ ${ }^{*}$ Department of Clinical Chemistry, University of Uppsala, Sweden
}

\begin{abstract}
Summary Chorionic gonadotrophin activity in extracts of the term placenta of a dolphin, a sea lion and a grey seal was measured by its effectiveness in increasing uterine weight in the mouse and by solid-phase RIA using hCG as immunogen and labelled antigen. Bioreactive (B) gonadotrophin was found in these placentae and, compared to the human term placenta, the concentration of CG in the dolphin was higher, in the sea lion similar and in the grey seal lower. The biological activity in each species was neutralized with a rabbit anti-hCG serum. All placental extracts contained material active in the $\mathrm{hCG}$ immunoassay (I). The ratio $\mathrm{B} / \mathrm{I}$ was significantly higher for the $C G$ in the placental extracts of the marine mammals compared with that of the human term placenta. Results of in-vivo bioassay, RIA, electrophoretic and gelchromatographic studies indicate structural similarities between CG in the placentae of the marine mammals and human CG.
\end{abstract}

\section{Introduction}

Contributions to the reproductive endocrinology of marine mammals have been mostly of a morphological nature (Harrison, 1951, 1960, 1963; Harrison, Matthews \& Roberts, 1952; Laws, 1956; Amoroso et al., 1965; Harrison \& Young, 1966; Sinha \& Erickson, 1972; Bigg \& Fisher, 1974; Boshier, 1977, 1981; Sinha, Erickson \& Seal, 1977). However, in recent years some plasma steroids have been measured during pregnancy and post partum in a few species of seal (Daniel, 1974, 1975; Liggins, France, Knox \& Zapol, 1979; Raeside \& Ronald, 1981; Boyd, 1983). Until recently the concentration of protein and steroid hormones in placentae of marine mammals seems to be confined to a single estimation of progesterone (Harrison, 1960). Hobson \& Boyd (1984) have shown that progesterone and a biologically active chorionic gonadotrophin (CG) is present in the placenta of the grey seal (Halichoerus grypus). These results point to the placenta as the source of a luteinizing hormone which Amoroso, Harrison, Matthews \& Rowlands (1951) suggested was most probably responsible for the precocious enlargement of the gonads of fetal grey seals.

The present investigation is concerned with providing information about $\mathrm{CG}$ and its subunits in the term placenta of a grey seal, a bottle-nosed dolphin and a Californian sea lion. For comparison a human term placenta was included in the investigation.

\section{Materials and Methods}

A term placenta was obtained from a captive bottle-nosed dolphin (Tursiops truncatus), a captive Californian sea lion (Zalophus californianus), a grey seal (Halichoerus grypus) shot at the Farne Islands and a human placenta obtained after a normal delivery and gestation of 41 weeks. In the 
dolphin, sea lion and seal gestation is approximately 12 months. Delayed implantation of about 3 months occurs in the sea lion and seal. The animal placentae and membranes were frozen at $-20^{\circ} \mathrm{C}$ before being sent to the laboratory. The human placenta was not frozen and was dealt with soon after delivery.

\section{Extraction of placental gonadotrophin}

The frozen placentae were thawed, dissected free from umbilical cord and membranes and weighed. Half of each placenta was homogenized in ice-cold acetone and ice-cold diethyl ether (5:1, $\mathrm{v} / \mathrm{v}, 6 \mathrm{ml} / \mathrm{g}$ ). The human placenta was treated similarly except that all of it was used. The homogenized tissue was kept at $4^{\circ} \mathrm{C}$ overnight and collected by filtration on a Buchner funnel. The tissue residue was washed in acetone and ether during filtration after which drying was completed in a desiccator over Dryerite. This method of extraction has been shown to remove steroids present in the primate placenta (Hobson, 1972). The desiccated placental material was disintegrated in $0.9 \%$ $(\mathrm{w} / \mathrm{v}) \mathrm{NaCl}$ in a high-speed tissue grinder (Ultra turrax), left overnight at $4^{\circ} \mathrm{C}$, centrifuged and the supernatant assayed.

\section{In-vivo bioassay}

The gonadotrophic activity of placental extracts and the hCG standard was measured by its effectiveness in increasing uterine weight of immature female mice. The method was essentially that of Levin \& Tyndale (1937) in which mice were injected subcutaneously with one third of the total dose on 3 consecutive days and killed $72 \mathrm{~h}$ after the first injection. Uteri, dissected free from mesentery, fat, ovaries and oviducts, were cut at the uterocervical junction. Intrauterine fluid was expressed between filter paper before the uterus was weighed to the nearest $0.1 \mathrm{mg}$ on a torsion balance. Five or 10 mice were used at each of 3 dose levels, a log dose interval of 0.301 of the unknown and the hCG standard preparation being assayed simultaneously. Estimations of relative potency of the placental extracts were expressed per $g$ wet weight as International Unit equivalents of the Second International Standard for hCG (i.u. hCG, WHO code 61/16). The smallest amount of hCG which produced a significant $(P<0.01)$ response in the bioassay, compared with that in saline injected controls, was $0.0625 \mathrm{i}$.u. The response parameter was the logarithm of the mouse uterine weight.

\section{Antiserum to hCG}

The antiserum was a rabbit anti-hCG preparation raised against an hCG preparation (Gonadex, Leo, Sweden) having a biological activity of $5000 \mathrm{i} . \mathrm{u} . / \mathrm{mg}$. This antiserum was used to see if it would neutralize the gonadotrophic activity of the 4 placental extracts. These and the hCG standard were assayed with the addition of antiserum or normal rabbit serum (NRS). The amount of antiserum used was $15 \mu \mathrm{l}$ per total dose per mouse.

\section{Gel chromatography}

An amount of dolphin, sea lion, grey seal and human placental tissue extract equivalent to respectively $34.2 \mathrm{mg}, 56.0 \mathrm{mg}, 375.0 \mathrm{mg}$ and $480.0 \mathrm{mg}$ was dissolved in $0.9 \%(\mathrm{w} / \mathrm{v}) \mathrm{NaCl}$ and dialysed before chromatography on a $26 \times 930 \mathrm{~mm}$ Sephadex G-200 column, equilibrated with $0.1 \mathrm{M}-$ Tris- $\mathrm{HCl}$ buffer of $\mathrm{pH} 7.5,0.2 \mathrm{M}-\mathrm{NaCl}$. Yhe flow was against gravity with a rate of $9 \mathrm{ml} / \mathrm{h}$ and 3-ml fractions were collected and assayed by solid-phase radioimmunoassays for hCG, and the alpha and beta subunits of hCG. The degree of retardation on the column, expressed in $K_{\mathrm{av}}$ values (Laurent \& Killander, 1964) where $K_{\mathrm{av}}=\left(\mathrm{V}_{\mathrm{e}}-\mathrm{V}_{\mathrm{o}} / \mathrm{V}_{\mathrm{t}}-\mathrm{V}_{\mathrm{o}}\right)$ and $\mathrm{V}_{\mathrm{e}}$ is the elution volume of the sub- 
stance, $V_{0}$ is the void volume and $V_{t}$ is the total bed volume, was compared with that of purified preparations of hCG and its subunits similarly treated.

\section{Zone electrophoresis in agarose suspension}

Zone electrophoresis in agarose of the placental extracts was performed in a column, $1.3 \mathrm{~cm} \times 67 \mathrm{~cm}$, with $0.17 \%$ agarose (Agarose C, Pharmacia Fine Chemicals, Uppsala, Sweden) suspension in 0.075 M-sodium veronal buffer ( $\mathrm{pH} \mathrm{8.6)} \mathrm{according} \mathrm{to} \mathrm{the} \mathrm{method} \mathrm{of} \mathrm{Hjerten} \mathrm{(1963)}$ with some modifications (Wide, 1981). Samples of 100-500 $\mu$ l of the extracts, together with trace amounts of labelled hCG, labelled human serum albumin (HSA), were added to $0.3-0.5 \mathrm{ml}$ serum from a child. One volume of the mixture was added to an agarose pellet obtained by centrifugation of 2 volumes agarose suspension. Application of the sample was performed by layering as described by Hjertén (1963). Electrophoresis was performed at a current of $50 \mathrm{~mA}$ for about $20 \mathrm{~h}$. After electrophoresis the agarose suspension was pumped out through a funnel fitted with tubing to a sample collector and the agarose was then removed by centrifugation. The supernatant, without further treatment, was analysed for CG activity by RIA. The migration rate of labelled HSA was about $12 \mathrm{~cm}^{2} \cdot \mathrm{s}^{-1} \cdot \mathrm{V}^{-1}$. The migration rate of the activity of a hormone was expressed as a percentage of that of labelled HSA. The electrophoretic migration velocities in the agarose suspension are similar to those in a free solution and related to molecular charge in the particular buffer solution. A difference in migration rate is directly proportional to a difference in charge.

\section{Radioimmunoassay}

The immunoactivities of the saline extracts, before and after chromatography, were assayed by solid-phase radioimmunoassays (Wide, 1969) for hCG, and the alpha and beta subunits of hCG. An hCG preparation (13 000 i.u./mg by bioassay and 7500 i.u./mg by radioimmunoassay) was supplied by AB Leo (Sweden), and the hCG-alpha- and beta-subunits and their antisera (SA6 and SB6) by NIAMDD, National Institutes of Health, Bethesda, MD, U.S.A. The purified preparation of hCG and its subunits were labelled with ${ }^{125} \mathrm{I}$ by the chloramine T technique (Greenwood, Hunter \& Glover, 1963).

The Second International Standard for hCG was used as a reference preparation in the hCG assays of the placental extracts before chromatography. The sensitivity of the hCG assays was about $0 \cdot 1 \mathrm{mU}$ per test tube. The hCG assays of the unfractionated extracts were made as $3 \times 3$ assays with 4 replicates at each dose level with a log dose interval of 0.3010 for the standard and the unknown. The immunoreactivity of the material after chromatography was expressed in $\mu \mathrm{g} / \mathrm{l}$ using purified preparations as reference standards.

\section{Statistical analysis}

Results of all bioassay, immunoassays, and tests of validity (linearity, parallelism and index of precision expressed as $\lambda$ ) were calculated according to Gaddum (1953).

\section{Results}

\section{$C G$ activity in placental extracts}

Extracts of a dolphin, a sea lion, a grey seal and a human placenta contained measurable amount of biologically (B) and immunologically (I) active gonadotrophin (Table 1). The concentration of biologically active CG in these placentae was higher in the dolphin, similar in the sea lion and lower in the seal compared with the human. The concentration of immunologically active 
Table 1. Concentration of bio- and immuno-reactive CG in the term placenta of a dolphin, a sea lion, a grey seal and a woman

\begin{tabular}{lcccc}
\hline & $\begin{array}{c}\text { Placenta dissected } \\
\text { wet wt }(\mathrm{g})\end{array}$ & Bioassay $(\mathrm{B})$ & Immunological assay $(\mathrm{I})$ & $\mathrm{B} / \mathrm{I}$ \\
\cline { 3 - 5 } Material & 1076 & $271(251-293)^{*}$ & $55(51 \cdot 6-58 \cdot 4)$ & $4 \cdot 93$ \\
Dolphin & 745 & $43(38-44)$ & $8(7 \cdot 5-8 \cdot 5)$ & $5 \cdot 30$ \\
Sea lion & 1153 & $0 \cdot 53(0 \cdot 460 \cdot 61)$ & $0 \cdot 25(0 \cdot 23-0 \cdot 27)$ & $2 \cdot 20$ \\
Seal & 360 & $27 \cdot 7(22 \cdot 8-33 \cdot 1)$ & $32 \cdot 1(27 \cdot 3-37 \cdot 9)$ & $0 \cdot 86$ \\
Human & & &
\end{tabular}

*Estimates of potency and their $95 \%$ fiducial limits, in parentheses, expressed in i.u. equivalents of the Second International Standard for hCG (WHO code 61/6).

CG was higher in the dolphin, but lower in the sea lion and seal than it was in the human placental extracts. The ratio between the biological and immunological (B/I) CG activity in the extracts of the marine mammals placentae was significantly higher compared with that of the human term placenta (Table 1).

No significant $(P<0.05)$ departure from parallelism or linearity was observed between log dose and $\log$ response of the placental extracts and the hCG standard preparation in either the biological or immunological assays. An index of precision $(\lambda)$ was calculated for each assay and the mean value for $\lambda$ was 0.056 in the bioassays and the corresponding value for the immunoassays was $0 \cdot 030$.

\section{Neutralization of placental CG activity}

The effect of a rabbit anti-hCG serum upon the biological activity of the hCG standard preparation and upon the extracts from the placentae of the marine mammals and the human is shown in Table 2. The mean uterine weight of mice injected with these placental extracts or with the hCG standard plus hCG antiserum was, at all dose levels, significantly $(P<0.0001)$ smaller than those of mice injected with the hCG standard or placental extracts plus normal rabbit serum (NRS).

Table 2. Neutralization with an anti-hCG serum of the biological activity of term placental extracts and the hCG standard preparation

\begin{tabular}{|c|c|c|c|}
\hline \multirow[b]{2}{*}{ Material } & \multirow[b]{2}{*}{ Dose } & \multicolumn{2}{|c|}{ Mean \pm s.e.m. uterine wt $(\mathrm{mg})^{*}$} \\
\hline & & With antiserum & Without antiserum \\
\hline Dolphin placenta & $\begin{array}{l}0.045 \mathrm{mg} \\
0.090 \mathrm{mg} \\
0.18 \mathrm{mg}\end{array}$ & $\begin{array}{l}6.8 \pm 0.09 \\
6.9 \pm 0.07 \\
7.0 \pm 0.14\end{array}$ & $\begin{array}{l}12 \cdot 0 \pm 0 \cdot 35 \\
22 \cdot 2 \pm 1 \cdot 14 \\
45 \cdot 2 \pm 2 \cdot 69\end{array}$ \\
\hline Sea lion placenta & $\begin{array}{l}0.60 \mathrm{mg} \\
1.20 \mathrm{mg} \\
2.40 \mathrm{mg}\end{array}$ & $\begin{array}{l}6.7 \pm 0.11 \\
7.5 \pm 0.18 \\
8.9 \pm 0.36\end{array}$ & $\begin{array}{l}10 \cdot 2 \pm 0 \cdot 40 \\
20 \cdot 0 \pm 1 \cdot 03 \\
40 \cdot 5 \pm 2 \cdot 41\end{array}$ \\
\hline Seal placenta & $\begin{array}{l}42.5 \mathrm{mg} \\
85.0 \mathrm{mg}\end{array}$ & $\begin{array}{l}8.0 \pm 0.45 \\
7.8 \pm 0.53\end{array}$ & $\begin{array}{l}11 \cdot 0 \pm 0.24 \\
20 \cdot 6 \pm 0.73\end{array}$ \\
\hline Human placenta & $\begin{array}{l}0.7 \mathrm{mg} \\
1.4 \mathrm{mg}\end{array}$ & $\begin{array}{l}6 \cdot 8 \pm 0.05 \\
7 \cdot 4 \pm 0.28\end{array}$ & $\begin{array}{l}13 \cdot 5 \pm 0.98 \\
25 \cdot 7 \pm 2.53\end{array}$ \\
\hline hCG standard & $\begin{array}{l}0.0625 \text { i.u. } \\
0.125 \text { i.u. } \\
0.25 \text { i.u. }\end{array}$ & $\begin{array}{l}7.2 \pm 0.19 \\
7.5 \pm 0.32 \\
8.6 \pm 0.32\end{array}$ & $\begin{array}{l}10 \cdot 6 \pm 0.30 \\
20 \cdot 1 \pm 0.73 \\
44.5 \pm 2.09\end{array}$ \\
\hline Saline control & $3.0 \mathrm{ml}$ & & $7 \cdot 1 \pm 0 \cdot 13$ \\
\hline Mouse pituitary & 8 glands & $25 \cdot 3 \pm 1 \cdot 46$ & $26 \cdot 6 \pm 1 \cdot 28$ \\
\hline
\end{tabular}

${ }^{*} n=5$ except for saline control for which $n=10$. 

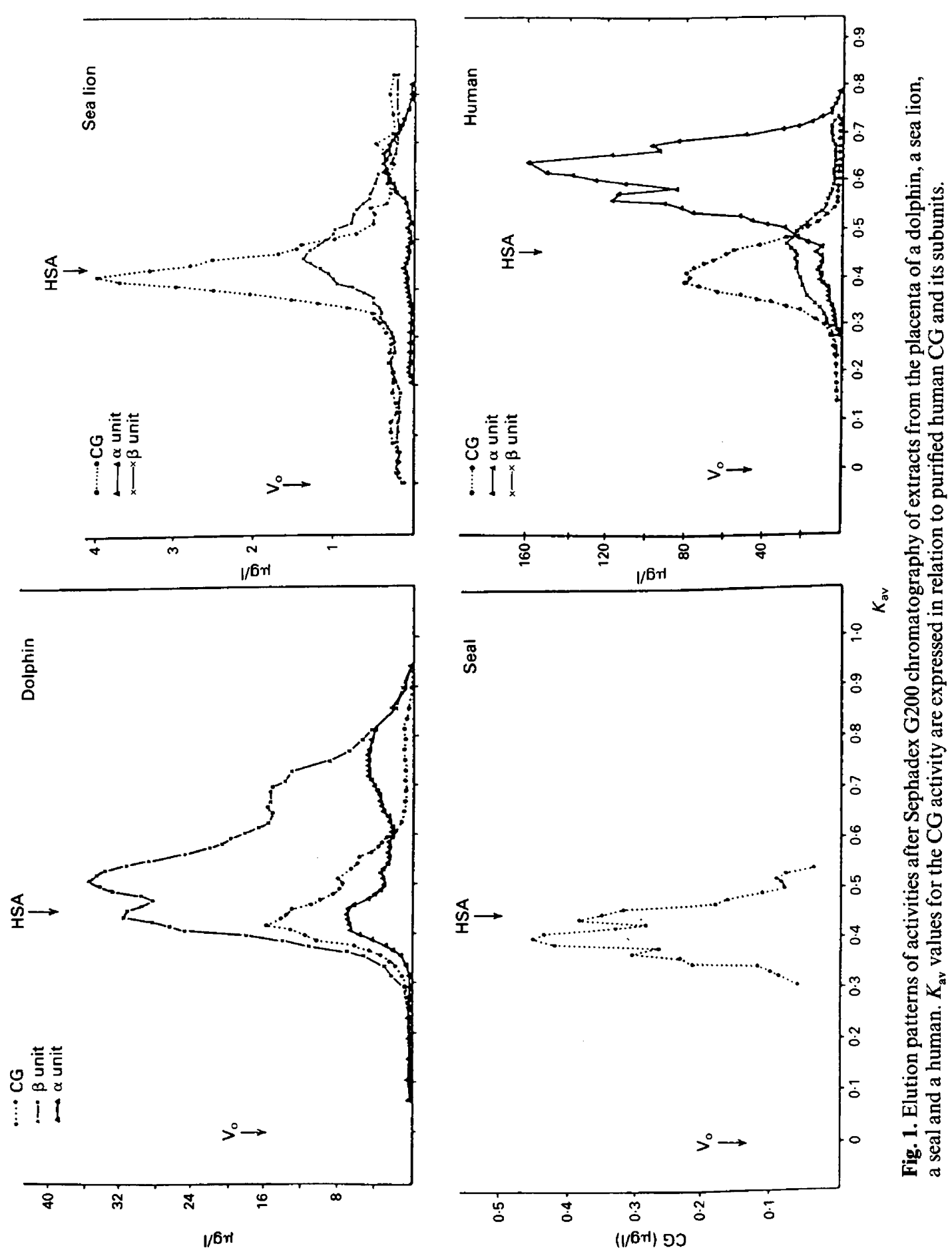


\section{Chromatographic studies}

The elution patterns obtained after Sephadex G-200 chromatography of the placental extracts are shown in Fig. 1. The extracts from the 4 placentae had, with the exception of that from the seal, a significant activity after column chromatography in the RIAs for hCG and hCG alpha and beta subunits. The activities were expressed in relation to those of highly purified hCG and subunit preparations. The $K_{\mathrm{av}}$ values for the CG activity in the extracts from the 4 placentae were close, $0 \cdot 40-0 \cdot 43$. The relative amount of beta subunit activity was high in the dolphin placental extract while the alpha subunit predominated in the human placental extract. The amounts of free subunits were very small in the sea lion and not detectable in the seal extract.

\section{Zone electrophoresis}

Elution patterns of immunoreactive CG activity after zone electrophoresis are shown in Fig. 2. The migration rate of each fraction was expressed as a percentage of that of labelled human serum albumin (HSA). The median migration rate of CG, calculated for the dolphin, sea lion, grey seal and human placental extracts, was $38,39,37$ and 34 respectively.
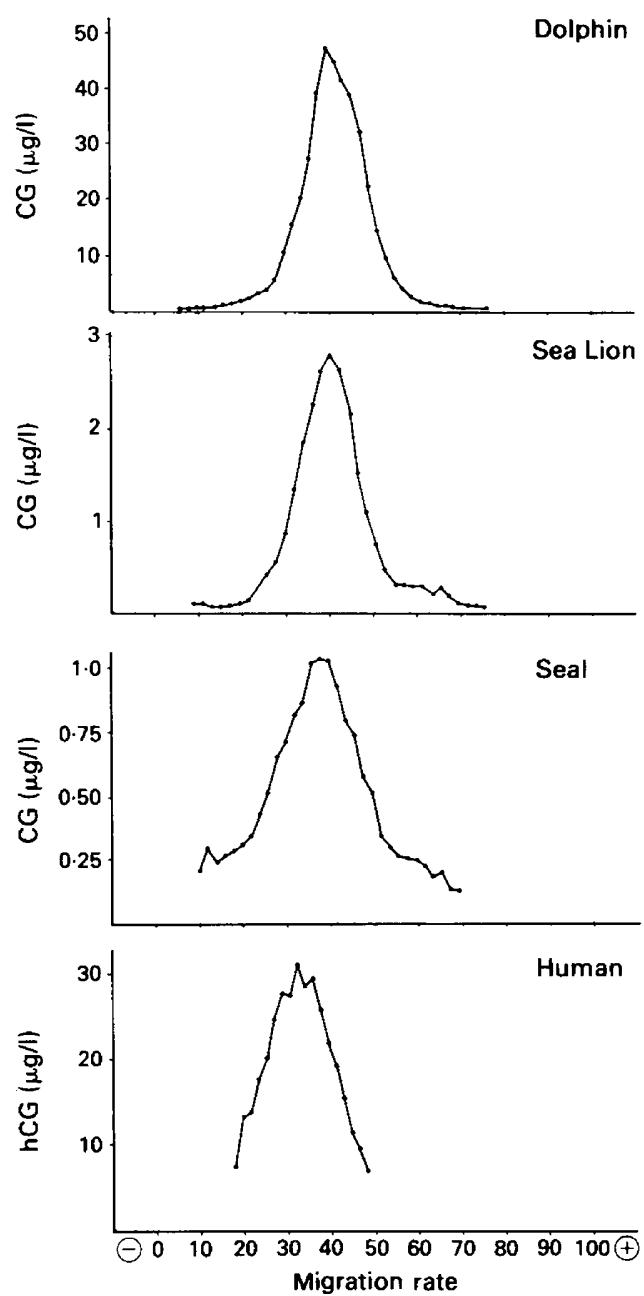

Fig. 2. Elution patterns of immunological CG activity of extracts from the placenta of a dolphin, a sea lion, a seal and a human. Migration rate of each fraction is expressed as percentage of that labelled HSA. 


\section{Discussion}

In the present study biologically and immunologically active CG was found in the placental extracts of the dolphin, sea lion, grey seal and the human. The concentration of bioreactive CG varied from $0.25 \mathrm{i} . u$./g for the seal to $271 \mathrm{i}$.u./g for the dolphin. The CG concentration in the dolphin term placenta is considerably higher than that of the human term placenta (Hobson \& Wide, 1974). CG concentrations with high biological activity are found in the human placenta early in pregnancy (Diczfalusy, 1953; Hobson, 1971) or in abnormal trophoblastic tissue of gestational and non-gestational origin (Hobson, 1965). The concentration of immunological CG in the human term placenta was similar in amount to the biological CG activity. However, extracts of term placenta from the marine mammals contained a significantly lower concentration of immunologically active CG compared with the biological activity. The difference between these two activities may be due to a lower cross-reactivity of placental CG in the homologous RIA for hCG. A relationship between charge and metabolic clearance rate has been observed for pituitary FSH (Wide, 1984). Small differences in charge were observed on the CG molecules, and if a similar relationship to FSH exists the higher in-vivo biological activity of the placental extracts may be due to their longer half life.

Subunit activity was found in all the placental extracts except that of the seal. Of particular interest is the relatively large amount of free beta subunit activity in the dolphin compared with the large amount of alpha subunits in the human term placenta. Franchimont, Gaspard, Reuter \& Heynen (1972) showed that when villi from human term placentae were cultured the amount of hCG and beta subunit in the medium was relatively low compared to the amount of alpha subunit present. They suggested that the synthesis of beta subunit might be the limiting factor in hCG production. Chatterjee \& Munro (1977) synthesized hCG from polyribosomes prepared from 1st trimester and term placentae and concluded that the amount of hCG produced was limited by the availability of the beta subunit. It is known that the tissue of some trophoblastic tumours contains large amounts of biologically and immunologically reactive hCG and have the hCG beta subunit as the major component (Vaitukaitis \& Ebersole, 1976; Vaitukaitis, 1978). It is remarkable that the dolphin placental $\mathrm{CG}$ is qualitively and quantitatively similar to that of abnormal human trophoblastic tissue.

The results obtained in this investigation suggest that the gonadotrophin in the placental extracts is substantially the same as hCG and the following similarities were observed. In the biological and immunological assays there was no departure from parallelism and linearity between the hCG standard preparation and the CG activity in the placental extracts. This CG activity in the placentae of the dolphin, sea lion and seal was, like the hCG activity in the human placenta and hCG standard preparation, neutralized by an anti-hCG serum. The extracts of placentae, with the exception of the grey seal, were shown to have subunit activity when measured in the RIA for the alpha and beta subunits of hCG. $K_{\mathrm{av}}$ values for CG activity in the extracts from the placentae of the marine mammals and the human placenta after gel chromatography indicate an apparent similarity in molecular size between the CG and hCG. The median migration rate of CG activity in the placental extracts of the marine mammals and that of the human were not very different.

The relative amounts of $C G$ subunits compared to $C G$ varied between species indicating that differences may exist with respect to hormone synthesis. Until more is known about the physiological role of CG in pregnancy, an explanation for observed differences between species in placental concentration of gonadotrophin and its subunits can only be speculative.

We thank Mr A. G. Greenwood for the dolphin and sea lion placentae; Dr I. L. Boyd for the grey seal placenta; and Mr C. Bengtsson, Miss Karin Eriksson and Mrs J. Flockhart for technical assistance. Financial support was provided by Organon Teknika Ltd and the Swedish Medical Research Council, Grant Number 637. 


\section{References}

Amoroso, E.C., Harrison, R.J., Matthews, L.H. \& Rowlands, I.W. (1951) Reproductive organs of near term and new born seals. Nature, Lond. 168, 771-772.

Amoroso, E.C., Bourne, G.H., Harrison, R.J., Matthews, L.H., Rowlands, I.W. \& Sloper, J.C. (1965) Reproductive and endocrine organs of foetal, new born and adult seals. $J$. Zool., Lond. 147, 430-486.

Bigg, M.A. \& Fisher, H.D. (1974) The reproductive cycle of the female harbour seal off Southeastern Vancouver Island. In Functional Anatomy of Marine Animals, Vol. 2, pp. 329-347. Ed. R. J. Harrison. Academic Press, London.

Boshier, D.P. (1977) Observations on the corpus luteum of the grey seal (Halichoerus grypus) at the time of ova implantation. In Functional Anatomy of Marine Animals, Vol. 3, pp. 333-359. Ed. R. J. Harrison. Academic Press, London.

Boshier, D.P. (1981) Structural changes in the corpus luteum and endometrium of seals before implantation. J. Reprod. Fert., Suppl. 29, 143-149.

Boyd, I.L. (1983) Luteal regression, follicle growth and the concentration of some plasma steroids during lactation in grey seals (Halichoerus grypus). J. Reprod. Fert. 69, 157-164.

Chatterjee, M. \& Munro, H.N. (1977) Changing ratio of human chorionic gonadotropin subunits synthesized by early and full term placental polyribosomes. Biochem. Biophys. Res. Commun. 77, 426-433.

Daniel, J.C. (1974) Circulating levels of oestradiol-17ß during early pregnancy in the Alaskan fur seal showing an oestrogen surge preceding implantation. $J$. Reprod. Fert. 37, 425-428.

Daniel, J.C. (1975) Concentrations of circulating progesterone during early pregnancy in the northern fur seal, Callorhinus ursinus. J. Fish. Res. Bd Can. 21, $773-811$.

Diczfalusy, E. (1953) Chorionic gonadotrophin and oestrogens in the human placenta. Acta endocr., Copenh., Suppl. 12, 1-175.

Franchimont, P., Gaspard, U., Reuter, A. \& Heynen, G. (1972) Polymorphism of protein and polypeptide hormones. Clin. Endocr. 1, 315-336.

Gaddum, J.H. (1953) Simplified mathematics for bioassays. J. Pharm. Pharmac. 5, 345-358.

Greenwood, F.C, Hunter, W.M. \& Glover, J.S. (1963) The preparation of ${ }^{131} \mathrm{I}$ labelled human growth hormone of high specific radioactivity Biochem. J. 89, $114-123$.

Harrison, R.J. (1951) Changes in the reproductive tract of foetal and adult seals. J. Anat. 85, 428 .

Harrison, R.J. (1960) Reproduction and reproductive organs in common seals (Phoca vitulina) in the Wash, East Anglia. Mammalia 24, 372-385.

Harrison, R.J. (1963) A comparison of factors involved in delayed implantation in badgers and seals in Great Britain. In Delayed Implantation, pp. 99-114. Ed. A. C. Enders. University of Chicago Press, Chicago.

Harrison, R.J. \& Young, B.A. (1966) Functional characteristics of the pinniped placenta. Symp. zool. Soc. Lond. 15, 47-68.

Harrison, R.J., Matthews, L.H. \& Roberts, J.M. (1952)
Reproduction in some pinnipedia. Trans. zool. Soc. Lond. 27, 437-531.

Hjertén, S. (1963) Zone electrophoresis in columns of agarose suspensions. J. Chromatogr. 12, 210-256.

Hobson, B.M. (1965) The hormone production of normal and abnormal trophoblast. In The Early Conceptus. Normal and Abnormal, pp. 121-129. Ed. W. W. Park. Thompson, Dundee.

Hobson, B.M. (1971) Production of gonadotrophin, oestrogens and progesterone by the primate placenta. Adv. Repr. Physiol. 5, 67-102.

Hobson, B.M. (1972) Gonadotrophin concentrations in the placentae of man, the rhesus monkey and the marmoset. Folia primat. 18, 35-40.

Hobson, B.M. \& Boyd, I.L. (1984) Gonadotrophin and progesterone concentrations in the placentae of grey seals (Halichoerus grypus). J. Reprod. Fert. 72, $521-528$.

Hobson, B.M. \& Wide, L. (1974) Chorionic gonadotrophin in the human placenta in relation to the sex of the foetus at term. J. Endocr. 60, 75-80.

Laurent, T.C. \& Killander, J. (1964) A theory of gel filtration and its experimental verification. $J$. Chromat. 14, 317-330.

Laws, R.M. (1956) The elephant seal (Mirounga leonina Linn). 3. The physiology of reproduction. Falk. Is. Dep. Serv. Sci. Rep. 15, 1-74.

Levin, L. \& Tyndale, H.H. (1937) The quantitative assay of "follicle-stimulating" substances. Endocrinology 21, 619-628.

Liggins, J.C., France, J.T., Knox, B.S. \& Zapol, W.M. (1979) High corticosteroid levels in plasma of adult and foetal Weddell Seals (Leptonychotes weddelli) Acta endocr., Copenh. 90, 718-726.

Raeside, J.I. \& Ronald, K. (1981) Plasma concentrations of oestrone, progesterone and corticosteroids during late pregnancy and after parturition in the harbour seal, Phoca vitulina. J. Reprod. Fert. 61, 135-139.

Sinha, A.A. \& Erickson, A.W. (1972) Ultrastructure of the corpus luteum of Antarctic seals during pregnancy. Z. Zellforsch. mikrosk. Anat. 117, 35-45.

Sinha, A.A., Erickson, A.W. \& Seal, U.S. (1977) Fine structure of the seminiferous tubules in antarctic seals. Cell Tiss. Res. 178, 183-188.

Vaitukaitis, J.L. (1978) Glycoprotein hormones and their subunits -immunological and biological characterization. In Structure and Function of the Gonadotropins, pp. 339-360. Ed. K. W. McKerns. Plenum Press, New York.

Vaitukaitis, J.L. \& Ebersole, E.R. (1976) Evidence for altered synthesis of human chorionic gonadotropin in gestational trophoblast tumors. J. clin Endocr. Metab. 42, 1048-1055.

Wide, L. (1969) Radioimmunoassay employing immunosorbents. Acta endocr., Copenh., Suppl. 142, 207-221.

Wide, L. (1981) Electrophoretic and gel chromatographic analyses of follicle-stimulating hormone in human serum. Uppsala J. med. Sci. 86, 249-258.

Wide, L. (1984) Charge and MCR of human FSH in relation to sex and age. Excerpta Medica Int. Congr. Ser. 652, 1409, Abstr. 